\title{
Annotations
}

\section{Steroid hormone receptors}

A hormone is classically defined as a physiological regulator synthesised by ductless glands and transported in plasma to act on target cells at a distant site. How the specificity of action is conferred remained unknown until target tissue was shown to contain receptors to which the hormone bound. It is now accepted that all classes of steroid hormones, including the vitamin D sterols, act by binding to intracellular receptor proteins. ${ }^{1}$

\section{Mechanism of action}

The non-protein bound or 'free' fraction of steroid in plasma enters target cells by passive diffusion where a specific, high affinity, low capacity cytoplasmic protein binds the steroid. The binding affinity, a measure of how avidly a receptor binds minute quantities of steroid, indicates the biological potency of a hormone. For example, dexamethasone has a binding affinity 20 times greater than cortisol for the glucocorticoid receptor. To discriminate hormone signal from other 'noise' the receptor must display specificity for a particular hormone-akin to a high signal to noise ratio in 'hi-fi' equipment.

Once formed the steroid receptor complex is activated by a presumed structural alteration to the receptor and translocated to the nucleus where it binds to acceptor sites on chromatin. Subsequent events are incompletely understood but there follows DNA directed, RNA mediated new protein synthesis and expression of biological function of the steroid. This unified concept applies to all classes of steroid hormones except androgens. Testosterone, the principal circulating androgen, is converted intracellularly by a $5 \alpha$ reductase enzyme to an active metabolite, dihydrotestosterone, before receptor binding.

\section{Measurement of steroid receptors}

Steroid receptors are distributed in many tissues of the body. The characteristics of steroid receptor binding have been studied largely in cytosol, prepared by ultracentrifugation of homogenised tissue obtained mainly from experimental animals. Human tissues such as breast, uterus, and prostate obtained at surgery are used to measure oestradiol, progester- one, and dihydrotestosterone receptors. Even the foreskin, usually redundant after circumcision, is a rich source of receptors useful for the study of androgen receptor binding. ${ }^{2}$ The discovery of steroid receptors in peripheral blood lymphocytes (glucocorticoid) and in fibroblasts (glucocorticoid, androgen, vitamin D) has increased the availability of target cells for study, particularly in children.

Steroid receptor binding is a reversible reaction, saturable at low steroid concentrations. Binding is measured by incubating a range of concentrations of radiolabelled steroid with either a cytosolic or whole cell receptor preparation. Parallel incubations with an excess of unlabelled steroid allows measurement of non-specific binding to other cellular components ('background noise'). Various mathematical transformations such as the Scatchard plot are used to make the saturation curve linear, from which the binding affinity and receptor concentration can be derived. ${ }^{1}$ More detailed analysis including binding to nuclei can be performed using techniques such as sucrose density gradient analysis and two dimensional gel electrophoresis.

\section{Clinical applications}

Steroid receptor analysis has been used in clinical practice for the management of endocrine related cancers and to investigate the underlying cause in syndromes associated with hormone resistance. Solid tumours of the breast, uterus, and prostate gland have received most study. Quantitation of oestrogen and progesterone receptors in breast carcinoma plays a pivotal role in the choice of treatment in patients with metastatic disease. Endocrine treatment for metastatic disease produces a favourable response in $60 \%$ to $80 \%$ of patients with oestrogen and progesterone receptor positive tumours as compared with a less than $10 \%$ response in receptor negative tumours. ${ }^{3}$ For uterine and prostatic carcinoma the relation between tumour receptor content and response to treatment is less clear.

Glucocorticoids are invariably used for some part of the treatment schedule in most leukaemias. In childhood acute lymphoblastic leukaemia the incidence of remission after glucocorticoid inclusive 
chemotherapy is directly related to the concentration of glucocorticoid receptors in peripheral lymphocytes. Furthermore, the receptor concentration at diagnosis correlates with the duration of complete remission and is independent of other prognostic factors such as age, sex, white cell count, and cell type. $^{4}$

\section{Syndromes associated with hormone resistance}

Albright ${ }^{5}$ first used the term target organ unresponsiveness in pseudohypoparathyroidism due to renal tubular resistance to the action of parathyroid hormone. Several disorders such as nephrogenic diabetes insipidus, insulin resistant diabetes mellitus, pseudohypoaldosteronism, familial glucocorticoid resistance, vitamin $\mathrm{D}$ dependent rickets, and testicular feminisation syndrome have now been ascribed to some defect in hormone receptor interaction. The latter two disorders associated with steroid hormone resistance are described in more detail.

Vitamin D dependent rickets. Originally called pseudovitamin D deficient rickets, this is an autosomal recessive condition characterised by clinical and biochemical features of classic vitamin D deficiency rickets but requiring large doses of vitamin $D$ for treatment. ${ }^{6}$ Most patients have decreased serum concentrations of 1,25dihydroxyvitamin D (type I), where the presumed cause is deficiency of $1 \alpha$-hydroxylase enzyme required to convert 25-hydroxyvitamin $\mathrm{D}$ to its active metabolite. Some patients, however, have normal or increased serum concentrations of the active vitamin D metabolite (type II). The lack of response to physiological doses of 1,25-dihydroxyvitamin D suggests resistance to the action of this steroid on target tissues.

Since intestine, bone, and kidney are inaccessible to measure vitamin D receptor binding, it is fortunate that specific, high affinity receptors for 1,25 dihydroxyvitamin $D$ have been found in human skin fibroblasts. Recent studies have shown a variety of defects in steroid binding including absent nuclear retention of radiolabelled 1,25-dihydroxyvitamin $\mathrm{D}$ and receptor positive resistance associated with impaired induction of 24-hydroxylase activity. ${ }^{78}$

Testicular feminisation syndrome. The name given to this syndrome was first coined by Morris in 1953 when he reported a series of patients with a normal female phenotype but an XY karyotype and testes. ${ }^{9}$ The diagnosis is established either in infancy because of inguinal swellings or more usually at puberty because of primary amenorrhoea. Plasma testosterone concentrations are slightly above the normal adult male range but there are no signs of virilisation in adults with the classic syndrome. Variations of the syndrome where the external genitalia are partially virilised may present as ambiguous genitalia of the newborn. Other causes of male pseudohermaphroditism such as a defect in testosterone biosynthesis must be excluded. Terminology used more recently refers to complete and partial androgen insensitivity syndrome. ${ }^{10}$ The mechanism of androgen resistance has been extensively investigated in this syndrome after the development of reliable in vitro steroid receptor assays using fibroblasts cultured from genital skin. ${ }^{11}$ Complete and partial androgen insensitivity syndrome may be subdivided into receptor positive and negative variants based on quantitative receptor analysis. Recent qualitative studies of steroid binding in cells from receptor positive patients suggest that possible structural abnormalities of the receptor protein account for the phenotypic expression of androgen resistance. ${ }^{12}$ No abnormality of the androgen receptor can be found in some patients, using techniques currently available. Additional post-receptor defects involving transcription of messenger RNA and new protein synthesis are likely to be discovered once problems of methodology are resolved. Not only is androgen receptor analysis useful in diagnosis but it may influence a decision on the sex of rearing in male pseudohermaphroditism. Preliminary evidence indicates that androgens augment androgen receptor binding in vitro; this may serve as a bioassay to predict responsiveness to exogenous androgens in vivo (personal observation).

The mode of inheritance for both variants of androgen insensitivity syndrome is $\mathrm{X}$ linked recessive. The heterozygote cannot be detected reliably by current methods, although the discrimination is improved when receptor analysis is performed on cloned cells.

\section{Future developments}

The mechanism of steroid hormone action on target cells has found ready application in the investigation and management of several endocrine related disorders. The processes of steroid receptor binding to nuclei, gene transcription, and specific protein synthesis, however, remain poorly understood. More refined techniques to isolate and purify receptors, the development of monoclonal antibodies, and the use of specific DNA sequences will result in an improved understanding of steroid receptor interaction. 


\section{References}

1 Baxter JD, Funder JW. Hormone receptors. N Engl J Med 1979;301:1149-61.

2 Cunningham GR, Lobl TJ, Cockrell C, Shao TC, Tindall DJ. Characterization of steroid binding specificity of the androgen receptor in human foreskin fibroblasts. Steroids 1983;41:617-26.

${ }^{3}$ McCarty KS, Jr, Lubahn DB, McCarty KS. Oestrogen and progesterone receptors: physiological and pathological considerations. Clin Endocrinol Metab 1983;12:133-54.

4 Lippman M. Clinical implications of glucocorticoid receptors in human leukaemia. Am J Physiol 1982;243:E103-8.

5 Albright F, Burnett CH, Smith PH, Parson W. Pseudohypoparathyroidism - an example of 'Seabright-Bantam' syndrome. Endocrinology 1942;30:922-32.

6 Fraser D, Kooh SW, Kind HP, Holick MF, Tanaka Y, Deluca HF. Pathogenesis of hereditary vitamin D-dependent rickets: an inborn error of vitamin D metabolism involving defective conversion of 25-hydroxyvitamin D to 1,25-dihydroxyvitamin D. N Engl J Med 1973;289:817-22.

${ }^{7}$ Liberman UA, Eil C, Marx SJ. Resistance to 1,25dihydroxyvitamin D. Association with heterogeneous defects in cultured skin fibroblasts. J Clin Invest 1983;71:192-200.
${ }^{8}$ Griffin JE, Zerwekh JH. Impaired stimulation of 25 hydroxyvitamin D-24-hydroxylase in fibroblasts from a patient with vitamin D-dependent rickets, type II. J Clin Invest 1983;72:1190-9.

9 Morris JM. The syndrome of testicular feminization in male pseudohermaphrodites. Am J Obstet Gynecol 1953;65: 1192-211.

${ }^{10}$ Berkovitz GD, Brown TR, Migeon CJ. Androgen receptors. Clin Endocrinol Metab 1983;12:155-73.

1 Brown TR, Migeon CJ. Cultured human skin fibroblasts: a model for the study of androgen action. Mol Cell Biochem 1981:36:3-22.

12 Evans BAJ, Jones TR, Hughes IA. Studies of the androgen receptor in dispersed fibroblasts: investigation of patients with androgen insensitivity. Clin Endocrinol (Oxf) 1984;20:93-105.

I A Hughes

Department of Child Health, Welsh National School of Medicine, Heath Park, Cardiff CF4 $4 X N$ 